\title{
INDIVIDUALISMO: LÓCUS DA DIFICULDADE DE LER E ESCREVER ENTRE UNIVERSITÁRIOS
}

\author{
Ivar César Oliveira de Vasconcelos*
}

\begin{abstract}
RESUMO:
Este artigo discute a dificuldade que os alunos universitários têm de ler e escrever, uma autêntica ausência intelectual, relacionando-a com o individualismo. São dois fenômenos sociais muito próximos, cujas relações estimulam a curiosidade do pesquisador. $\mathrm{Na}$ base do individualismo, está a concorrência e há, entre os estudantes, uma tendência para naturalizála, isto é, de perceberem-na como um fato normal e definitivo na sociedade. De maneira geral, os estudantes universitários não vêem problema nisso e até entendem que ela não impacta a formação de grupos nas salas de aula. Entretanto, verificou-se com a pesquisa que essa formação de grupos não é suficiente para a construção de uma cultura propícia à ativa interação intelectual. Inclusive, os estudantes sequer têm consciência dos verdadeiros motivos que impedem essa interação. Buscou-se inspiração em Durkheim e seu método explicativo sobre o individualismo e em Weber e seu método compreensivo de análise das motivações dos atores sociais, tomando cuidado em seguir certas recomendações de Bourdieu na elaboração de pesquisas. Portanto, a pesquisa tem no centro um objeto específico dificuldade de ler e escrever de alunos universitários - que é visto na sua relação com o individualismo. O estudo conclui que o individualismo é o lócus de realização da ausência intelectual e apresenta, a título de acréscimo aos objetivos da pesquisa, algumas práticas em sala de aula que podem ser aplicadas pelos professores.
\end{abstract}

PALAVRAS-CHAVE: Leitura; Escrita; Individualismo; Universitários; Concorrência;

\begin{abstract}
:
This article discusses the difficulty on reading and writing among college students, an authentic intellectual absence, making a relation with the individualism. Intellectual absence and individualism are two closely related social phenomenon, whose relation stimulates the curiosity of researchers. In the base of the individualism, there is the competition, and it can be perceived, among the students, a tendency of naturalization of it, what means they consider the competition a normal and definitive fact in society. In general, college students do not see nothing wrong about such situation and understand that the competition does not impact the formation of groups into the classroom. However, it was verified through such research that the formation of groups is not enough to build a proper culture of active intellectual interaction. In addition, students have no consciousness about the true reasons, which prevent such interaction. Important to this research was Durkheim, due to his explanatory method on individualism, as well as Weber, through his comprehensive method of analysis on the motivations of the social actors, following Bourdieu's regards on research methodology. So, such research focus on a specific object, which is the difficulty on reading and writing by college students, and the question is related to the individualism phenomenon. The studies concluded that the individualism is the locus where the intellectual absence completes itself and they present us, in addition to the aim of the research, some classroom practices that can be allocated by professors.
\end{abstract}

\footnotetext{
* Graduado em Filosofia. Especialista em Filosofia e em Reengenharia e Recursos Humanos. Professor universitário nos cursos de Administração de Empresas e de Direito. E-mail: ivcov@hotmail.com.
} 
KEY-WORDS: reading, writing, individualism, college students, competition.

\section{Introdução}

A dificuldade de ler e escrever, ou de interpretar textos, entre os estudantes universitários é um fenômeno social relacionado a outro, também de nosso tempo: o individualismo. Existe uma estreita vinculação entre a ausência dessa atividade intelectual, ou distância da reflexão, e o comportamento marcado pelo individualismo.

As questões que se colocam são: até que ponto o individualismo, presente na consciência coletiva, hoje, está vinculado a essa ausência? Qual o nível de aproximação entre os dois fenômenos? Quais as formas assumidas por essa ausência intelectual em decorrência dessa aproximação?

\section{Sobre a ausência intelectual}

Tomemos como exemplo a aplicação de provas nos diversos cursos de qualquer universidade. A dificuldade de ler e/ou escrever, aqui denominada ausência intelectual, é demonstrada nas respostas dos estudantes nas provas: muitas não têm nada a ver com as perguntas, outras formam um amontoado de palavras sem sentido e com vários erros ortográficos - o que deixa os professores desesperados durante a correção dos testes. Encontram-se erros ortográficos tais como "prelcupação", "comprenção", "atravez". Além disso, os estudantes geralmente buscam auxílio junto aos professores, durante as provas, porque sozinhos não conseguem entender as questões.

Estudantes afirmam que os textos são longos e complicados. Ou que não têm tempo para ler. Ou, ainda, que os professores passam textos porque não necessitariam, com isso, explicar os assuntos de forma mais efetiva aos estudantes. Estariam despreparados. Professores alegam que os estudantes não querem nada, não querem ler. Entretanto, estudantes e professores entendem que a capacidade de ler e escrever, pelo menos razoavelmente, vêm deteriorando muito entre os alunos. Claro que o problema não está circunscrito às universidades. Pesquisas nacionais apontam que mais de $40 \%$ dos estudantes da $4^{\mathrm{a}}$ série, por exemplo, não lêem ${ }^{1}$ e $75 \%$ dos brasileiros não dominam o exercício da leitura, sendo mais de $60 \%$ os que não sabem interpretar textos. ${ }^{2}$

O objetivo deste artigo não é discutir sobre causas da ausência intelectual focando estruturas de universidades, que seriam ruins - professores mal remunerados, prédios deteriorados, formação deficiente. Não é esse o ponto de discussão que se quer trazer.

Também não se trata de buscar causas em uma possível falta de leitura por parte das crianças - chegando o problema às universidades. Diferentemente da estatística mencionada acima, referente aos estudantes da $4^{\mathrm{a}}$ série, e para ficar em um exemplo significativo, recentemente a Secretaria de Estado de Educação de Minas Gerais (onde há o maior percentual de universidades do país) ${ }^{3}$ constatou que mais de $82 \%$ das crianças que ingressaram em 2004 no ensino fundamental, de nove anos, nas redes estaduais e municipais naquele Estado liam e escreviam ao final do ciclo de alfabetização. ${ }^{4}$

Por último, não entendemos que o problema existe por causa de um "contágio geral". Isto é, não se trata de uma imitação generalizada e mútua de comportamentos que poderia inspirar frases como "ninguém ler mesmo, por isso não vou ler também”. Segundo Durkheim,

\footnotetext{
${ }^{1}$ http://www.educacao.mg.gov.br.

2 Correio Braziliense, Brasília, 11 de junho de 2006.

${ }^{3}$ O Estado possuía, em 2003, 265 das 1.859 existentes no país (14\% do total). Fonte: http://www.inep.gov.br.

${ }^{4}$ http://www.educacao.mg.gov.br.
} 
a imitação é a ausência de uma operação intelectual entre o que se "viu" antes de um ato e o próprio ato (ARON, 2002, p. 480). Não é o que acontece nesse caso, pois ao decidir não ler porque um colega de sala de aula não o faz, o estudante pensa e escolhe conscientemente pela não leitura. Não deixa de raciocinar, não sendo, portanto, uma imitação. Se o problema da ausência intelectual fosse causado pela imitação, bastaria, para resolvê-lo, que se afastassem os estudantes que lêem dos que não lêem.

$\mathrm{Na}$ verdade, trata-se de compreender o fenômeno social da ausência intelectual, considerando atentamente a sua natureza e complexidade, cuidando para não deformá-lo ou reduzi-lo.

\section{Sobre o individualismo}

Vale lembrar que a perda de capacidade da boa leitura e escrita ocorreu simultaneamente ao fortalecimento do individualismo, cada vez mais presente na sociedade, nesses tempos de grande liberdade entre as pessoas, do mercado aberto e da globalização. É mais fácil se comunicar, mas é maior o individualismo. Há mais chances de integração, é óbvio. Mas que integração? Para que? As relações ocorrem, na maioria das vezes, pela busca, de cada um, a seu modo, da realização imediata de interesses: qualificação profissional, crescimento na carreira, realização de uma pós-graduação, melhores salários, compra do apartamento, conforto da família, prazer e tantos outros exemplos. É assim que tem funcionado a sociedade. As pessoas são diferentes, pensam de várias maneiras, decidem e agem de acordo com os seus interesses e a sua função social.

O conjunto dessas "experiências de vida" está na base da formação da sociedade. Tanto as experiências positivas como as negativas. Verifica-se que os ritmos impostos pelas exigências de uma sociedade caracterizada pela competição levam ao individualismo, assim como ao isolamento.

Entendendo a sociedade como um organismo vivo, cada indivíduo desempenha um papel que está vinculado ao todo, dando movimento e vida ao coletivo. Nosso tempo é marcado pela forte presença do individualismo, que se refina, por assim dizer, permanentemente.

Tanto pior, quando esse individualismo resulta em maior distanciamento entre consciências, isto é, os indivíduos (estudantes, por exemplo) não debatem, não discutem temas importantes e reais. Não problematizam a realidade.

\section{Definição do problema investigado e definição das hipóteses}

O problema científico é o estudo das relações entre um fenômeno social, a ausência intelectual, e um outro fenômeno, também social, o individualismo. O problema foi percebido em função das circunstâncias apresentadas no meio acadêmico. O quadro de referência que conduziu à sua definição foi constituído pelas vivências do professor-pesquisador em sala de aula (provas, trabalhos, discursos), pelas teorias relacionadas ao tema ${ }^{5}$ e conceitos $^{6}$, bem como valores, tais como ansiedades dos alunos por não conseguirem ler e escrever como gostariam, preocupações com o mercado de trabalho (LAVILLE e DIONNE, 2006, p. 123).

O problema é fruto da curiosidade sobre o tema - lembrando que a sua discussão importa responsabilidade do pesquisador diante dos sujeitos da pesquisa (compromisso com a

\footnotetext{
${ }_{6}^{5}$ A metodologia utilizada teve como principais referências Durkheim e Weber.

${ }^{6}$ Vale ressaltar que a pesquisa não teve como objetivo principal aprofundar conhecimentos sobre os dois fenômenos sociais, mas simplesmente relacioná-los, com foco na problemática racional ora enunciada.
} 
preservação de identidades, fidelidade às informações, publicação deste artigo) e com a comunidade científica (eficácia, transparência, fidelidade ao método científico).

Assim, o problema da pesquisa encontra-se traduzido na pergunta: que relações existem entre a dificuldade que os alunos universitários encontram na leitura e na escrita e o individualismo?

A revisão de literatura conduziu-nos à elaboração das hipóteses. Não se pensou, inicialmente, em estabelecer vínculos entre elas. O objetivo era, apenas, confirmá-las sem se preocupar com a possibilidade de que elas estariam relacionadas intrinsecamente. Vê-las em espaços distintos: na sociedade, na sala de aula e nos relacionamentos entre os estudantes. Com a pesquisa, verificou-se uma seqüência entre as hipóteses, portanto uma conexão interna. Teve papel importante nessa verificação o fato de que uma parte da hipótese 01 (mostrada a seguir) não foi confirmada.

Finalmente, é importante dizer que este estudo foi realizado no pressuposto de que é sempre possível ampliar a discussão sobre o tema e métodos aplicados. Portanto, toda crítica será bem vinda.

\section{Método}

A suspeita de que o individualismo está vinculado intrinsecamente à questão da ausência intelectual levou-nos a realizar uma pesquisa junto a alguns estudantes dos cursos de Administração de Empresas e de Direito de uma grande universidade privada localizada em Brasília. Para saber até que ponto o individualismo está vinculado à ausência intelectual, elaboramos um roteiro contendo 26 afirmações e o distribuímos a 66 estudantes universitários (29 do curso de Administração de Empresas, do $5^{\circ}$ período, e 37 de Direito, do $2^{\circ}$ período) que opinaram segundo uma escala de concordância, indo de "concordo totalmente a discordo totalmente", com os níveis intermediários "concordo parcialmente e discordo parcialmente".

A pesquisa foi realizada na primeira semana de novembro de 2006, correspondendo, portanto, ao segundo bimestre do período universitário. Os 66 estudantes que participaram da pesquisa encontravam-se, à época de sua realização, submetidos à mesma metodologia de ensino-aprendizagem nas disciplinas Ciências Sociais e Ciências Políticas e Sociais. Antes, no bimestre anterior à pesquisa, haviam vivenciado o método expositivo que era sempre acompanhado por anotações no quadro. Quando a pesquisa foi realizada, a metodologia havia sido alterada em relação àquele bimestre e era, basicamente, "fracionamento" (ou painel simples) e "grupos para formulação de questões" (GIL, 1997, p. 69-86), sendo que eram entregues a eles os temas e os textos para que fossem trabalhados em sala. Na aula seguinte, o professor devolvia esse material, corrigido, para que houvesse uma nova discussão. A metodologia incluiu pequenas noções sobre lógica. Conceitos básicos, tais como "termo", "proposição", "argumentos", "extensão e compreensão", "falácia", aplicadas nos primeiros quinze minutos de aula, sempre vinculadas ao tema da aula ministrada na mesma data e conforme o conteúdo curricular.

$\mathrm{Na}$ investigação do problema da ausência intelectual, entendeu-se permanentemente que pesquisar é assumir uma atitude racional (e não uma espécie de busca mística), mesmo correndo o risco de ver cair por terra crenças que são do próprio pesquisador. O pressuposto norteador tem Bourdieu como referência, pois se entende que a pesquisa é "um discurso em que a gente se expõe, no qual se correm riscos" (BOURDIEU, 2006, p. 18). Neste caso, a compensação está na possibilidade de se tirar proveito da discussão, aprendendo, abrindo perspectivas, criando novas visões sobre o tema pesquisado e até contribuindo com possíveis soluções. 
As afirmações constantes no roteiro tiveram o objetivo de confirmar três hipóteses:

a) Os estudantes são conscientes de que a concorrência está na base da organização social, mas isso não impede a integração entre eles; ${ }^{7}$

b) A integração entre os estudantes não é suficiente para motivar a leitura e o gosto pela escrita e isso os leva à ausência intelectual;

c) Os estudantes não têm consciência dos verdadeiros motivos da ausência intelectual.

As proposições foram disponibilizadas, no roteiro, considerando os aspectos econômicos, sociais, políticos, culturais, pedagógicos, históricos e psicológicos. Em cada um desses aspectos, buscaram-se confirmações às hipóteses enumeradas acima. Além disso, foi disponibilizado no roteiro um espaço para anotações espontâneas.

Os estudantes foram orientados a considerar os termos "aluno" como sendo qualquer estudante universitário, "professor", o grupo de docentes de universidades, e "escola/universidade", outras instituições de ensino superior (pública ou privada). Assim, os estudantes deveriam partir de suas próprias experiências, na sua universidade, mas ampliando suas opiniões para outros universos tão reais quanto o seu. Eles foram avisados de que os dados seriam utilizados exclusivamente para promover a discussão acadêmica da situação problemática estudada e, nunca, em favor de represálias ou acusações.

Os dados obtidos foram organizados em tabelas, contendo categorias de acordo com os tipos de hipóteses e considerado os aspectos econômicos, sociais, políticos, culturais, pedagógicos, históricos e psicológicos. $\mathrm{Na}$ análise, houve influência do método durkheimiano.

Quanto aos discursos registrados espontaneamente pelos estudantes nos roteiros, os mesmos foram catalogados e, em seguida, serviram de base para interpretações segundo o método weberiano de analisar as motivações dos atores sociais.

Como se observa, a pesquisa está centrada em um objeto específico (dificuldade de leitura/escrita de alunos universitários) e encontra-se relacionada com o fenômeno do individualismo. O procedimento utilizado para sua compreensão está adequado ao objeto de estudo, pois foram utilizados métodos quantitativos e qualitativos. A abordagem escolhida, portanto, ficou a serviço do objeto de estudo e não o contrário.

As correlações estatísticas e as interpretações feitas com base nos discursos determinaram os tipos sociais do problema analisado e concluíram que a ausência intelectual tem vínculo direto com o distanciamento intelectual entre as pessoas, provocado pelo individualismo.

\section{Resultados}

Os resultados são evidenciados, a seguir, e estão classificados segundo as três hipóteses levantadas. As afirmações constantes no roteiro de pesquisa foram convertidas para "questões", visando fornecer uma melhor apresentação dos resultados. A palavra "grupo", que está presente nas questões, pretende traduzir a intenção de se reunir para aprimorar e desenvolver a leitura e a escrita.

\footnotetext{
7 Nossa hipótese 01, inicial, era: os estudantes são conscientes de que a concorrência está na base da organização social $e$ isso os afasta. Os resultados da pesquisa mostraram que a segunda parte da hipótese (em itálico) não era verdadeira. Ao invés de prejudicar na investigação, isso contribuiu para estabelecer um vínculo seqüencial entre as hipóteses 01 e 02 para, em seguida, estabelecer um outro vínculo entre as hipóteses 02 e 03.
} 
Gráfico 1 - Concorrência e Formação de Grupos

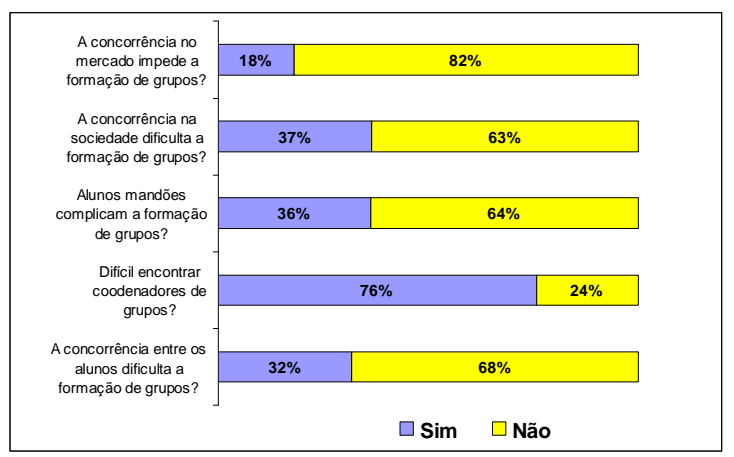

Gráfico 2 - Integração e Motivação para a Leitura/Escrita

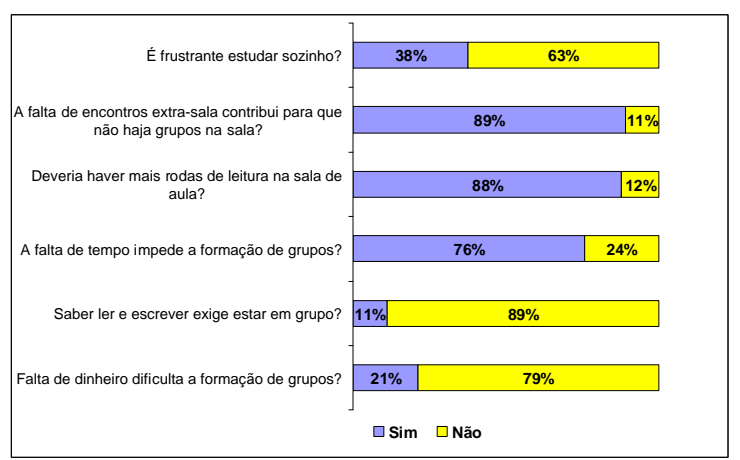

Gráfico 3 - Consciência das Causas (I)

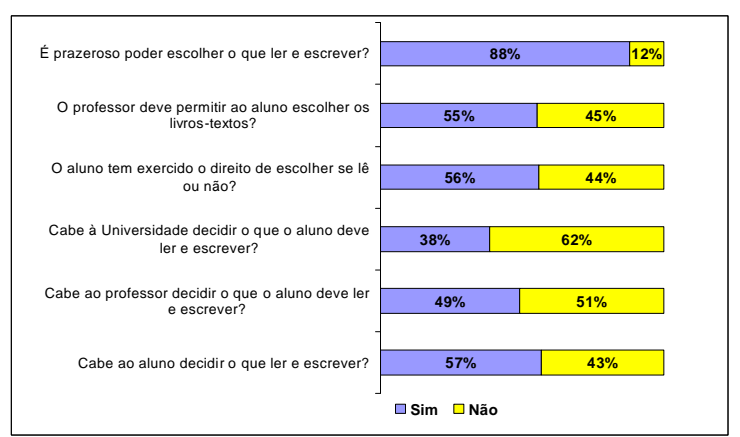

O roteiro incluiu afirmações, também relacionadas à consciência de causas, focadas diretamente no processo de ensino-aprendizagem:

Gráfico 4 - Consciência das Causas (II) 


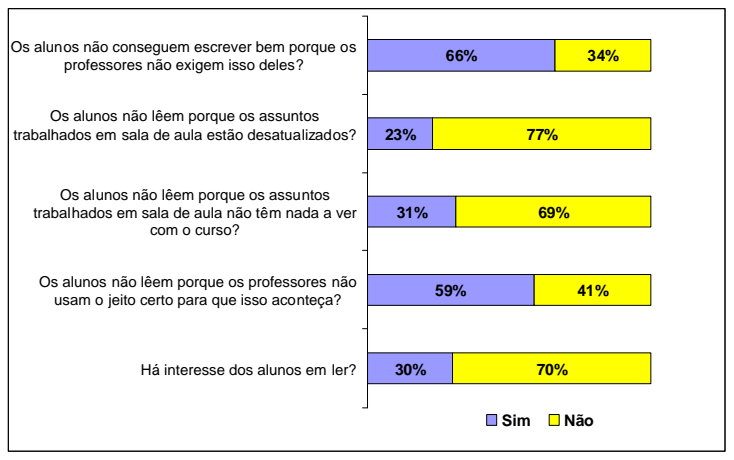

As anotações espontâneas estão classificadas, a seguir, segundo o curso realizado pelos estudantes ${ }^{8}$ :

Estudantes do curso de Administração de Empresas:

"Hoje em dia a leitura e a escrita está muito abaixo do que deveria estar nas universidades. por isso eu acho que deveria haver mais o incentivo dos professores para que isso possa melhorar".

"O grande problema é a falta de estímulo à leitura no período de formação do indivíduo".

"Na verdade essa falta de interesse do aluno de ler e escrever, vem desde o primário, onde os alunos não criam o hábito, mesmo que você peça para alguém que não gosta de ler, estudar alguma coisa, ele irá ler para alcançar um objetivo, ou um resultado, não por prazer de ler. Hoje em dia os estudantes têm muita preguiça de ler, mesmo estando cientes de que é necessário”.

"Existe a preguiça mental (também sou vítima) que faz com que nos afastemos de nossas vidas esse hábito, ler tem que ser um hábito".

"É muito importante abordar esse assunto para reforçar a grande importância do envolvimento, seja aluno ou professor, ao

${ }^{8}$ Os discursos estão transcritos ipsis litteris. 
que nos dispomos a fazer. De fato é real e gritante a desmotivação e interesse para se entregar aos estudos, compromissos, a vida em si”.

Estudantes do curso de Direito:

"A maioria dos alunos não estão preocupados em saber ler e escrever, mas sim no mercado de trabalho. $O$ diploma as vezes tem mais valor que uma formação academica proveitosa ".

"A leitura é uma atividade que está em falta, não apenas nas escolas, mas sim no Brasil inteiro, há pouca motivação do país em questão de leituras. Os livros passam do orçamento das famílias brasileiras, enquanto um bom livro no Brasil custa em média de 40 reais, em países desenvolvidos custa em média de 8 reais! Isso ocorre porque há um insentivo desde cedo a uma reparação econômica!".

"Acredito fielmente $e$ digo com veemência, que o principal interessado ée deve sempre ser o aluno, portanto, a iniciativa tem que partir deste, o profissional que leciona, é incubido de auxiliar o aluno, aperfeiçoar o que ele aprende ao longo de anos de estudo".

"Infelizmente, os alunos não apresentam a motivação e orientação necessários para que possa, por iniciativa própria, selecionar o que vai ler ou escrever. Isso obriga aos professores e coordenadores estabelecerem os assuntos a serem estudados e quais metas/prazos estipulados para leitura e produção de textos. Contudo, os efeitos não são os ideais (esperados), pois dependerá exclusivamente do aluno a disposição $e$ vontade de assimilar o 'currículo' ou 'ementa' abordados". 
"Ler mais que uma questão de hábito, é questão de gosto. Primeiro é preciso reconhecer em que direção vai sua leitura. Depois da minha primeira faculdade concluída, descobri o que realmente me atraía em relação à leitura."

\section{Discussões e Conclusões}

As discussões e as conclusões obtidas são demonstradas em duas perspectivas, que estão coerentes com a trajetória percorrida durante a pesquisa: dados objetivos e subjetivos. Nos dois casos, são feitas vinculações com as três hipóteses. As análises feitas com enfoque objetivo (perguntas direcionadas pelo pesquisador e cujos resultados são demonstrados nos gráficos) têm inspiração nas regras do método sociológico de Durkheim. As análises referentes ao aspecto subjetivo dos resultados (discursos espontâneos dos estudantes) baseiam-se no método compreensivo de Weber. ${ }^{9}$

Em seguida, são demonstradas três situações que surgem conforme o nível de aproximação entre os dois fenômenos sociais estudados - ausência intelectual e individualismo.

No final, e a título de acréscimo aos objetivos da pesquisa, são feitas sugestões baseadas nas falas dos estudantes e nas observações do professor-pesquisador. Sugerem-se práticas de ensino que contribuam para a concretização de uma presença intelectual - em oposição à ausência intelectual, definida e caracterizada na pesquisa em termos sociológicos.

Partindo do pressuposto de que a origem primeira de qualquer processo social de certa importância deve ser procurada na constituição do meio social interno (DURKHEIM, 2006, p. 104), é admissível que a causa da ausência intelectual esteja vinculada ao individualismo. O primeiro passo na busca desse vínculo foi dado por meio da verificação da hipótese 01, que se refere à concorrência entre os indivíduos e seu impacto na formação de grupos pelos alunos. O gráfico 1 mostra com que tranqüilidade a concorrência é percebida pelos alunos, que não vêem problema na formação de grupos por causa dela. Até admitem a dificuldade de encontrar coordenadores de grupos (76\% afirmaram isso). Então, se não há problema com a formação de grupos, por que não conseguem, nesses grupos, trocar experiências e aprimorar, ou até desenvolver, a capacidade de ler e escrever?

Pela hipótese 02, essa integração entre os alunos por meio dos grupos de estudos para ler e escrever não é suficiente para motivar a leitura e o gosto pela escrita. Em primeiro lugar, deveria haver mais rodas de leitura nas salas de aula, dizem os estudantes. Eles entendem que é em grupo que se aprende, pois $89 \%$ dos estudantes percebem a necessidade de formar grupos para "ler bem e escrever bem". No entanto, isso não causa frustração, dizem eles. O que, então, dificulta a formação de grupos de leitura e escrita? Não é, por exemplo, a falta de dinheiro. Seriam motivos como a falta de tempo e a pouca quantidade de oportunidades para se encontrarem. Mesmo que os estudantes saibam dessa necessidade e ainda que a

\footnotetext{
${ }^{9}$ Durante a investigação, buscou-se mobilizar todas as técnicas que pareciam ser pertinentes à definição do objeto de estudo e que pudessem ser utilizadas, considerando as condições práticas para a coleta de dados. A esse respeito, Bourdieu alerta que "a pesquisa é uma coisa demasiado séria e demasiado difícil para poder se tomar a liberdade de confundir a rigidez, que é o contrário da inteligência e da invenção, com o rigor, e se ficar privado deste ou daquele recurso entre os vários que podem ser oferecidos pelo conjunto das tradições intelectuais da disciplina (Sociologia) - e das disciplinas vizinhas (tais como): etnologia, economia, história" (BOURDIEU, 2006, p. 26).
} 
concorrência na sociedade não impeça a formação de grupos, por que não ocorre o aprendizado em grupos? Que condições poderiam ser criadas para que a ausência intelectual ocorresse?

A pesquisa demonstrou que os estudantes não conseguem, ainda, saber quais são verdadeiramente os motivos dessa ausência, pelo menos com relação ao individualismo. Mais da metade dos respondentes entende que cabe ao aluno decidir o que ler e escrever, até porque isso, inclusive, causa prazer, não cabendo à universidade e ao professor dizer a eles o que ler e escrever. Mais da metade dos estudantes entende que eles estão conseguindo exercer o direito de ler escrever. O que não é verdade, afirmamos. Nossa prática como educador tem demonstrado que a maioria dos estudantes de universidade confunde "ter o direito de escolher" com "exercer esse direito". O fato de se perceberem autônomos e capazes nessa tarefa em nada garante que estejam lendo e escrevendo (pelo menos razoavelmente).

Então, como fica confirmada a hipótese 03, a de que os estudantes não têm consciência dos motivos que levam à ausência? O gráfico 4 contém respostas que se referem a essa questão. Eles entendem que os temas trabalhados são pertinentes ao curso e estão atualizados. A causa da não leitura e elaboração de textos teria a ver com a falta de interesse dos próprios estudantes - assim eles se percebem - e com a inadequação das metodologias utilizadas pelos professores. Em suas respostas, eles aconselham os docentes a exigirem dos alunos mais leitura e elaboração de textos. Entendemos que apenas isto não basta. Compreendemos que a causa da ausência intelectual está vinculada ao individualismo presente na sociedade. Entretanto, de que individualismo se fala aqui?

A concepção durkheimiana da relação entre indivíduo e sociedade pode nos auxiliar nesse entendimento. Para Durkheim, os indivíduos são determinados pela realidade coletiva. Ao buscar o ponto limite dessa determinação, Durkheim estudou e identificou no suicídio ${ }^{10}$ egoísta o ápice do individualismo: trata-se de dar cabo a uma ação que depende exclusivamente de um único indivíduo. Segundo o pensador francês, as causas desse fenômeno patológico, na verdade dos três tipos de suicídio (egoísta, altruísta e anômico) seriam essencialmente sociais. $\mathrm{O}$ individualismo é o efeito de crenças, hábitos, costumes e tudo o mais que determina a consciência coletiva. É nele que o indivíduo, no limite da perda de sua própria história como referência para existir, opta por dizer um "não" a tudo isso e dá cabo à própria vida (ARON, 2002, p. 476-482).

De maneira análoga, e utilizando as análises feitas anteriormente, podemos explicar nosso problema da ausência intelectual: ela é um exemplo do limite do individualismo que predomina entre nós. Não ler e não escrever é uma opção que os estudantes têm em um contexto caracterizado por uma grande liberdade de agir e pensar. Percebendo-se acompanhado por seus pares, e entendendo que vive em grupo, o estudante opta por não ler e escrever porque entende que fazendo o contrário, ou seja, despendendo esforço na leitura e escrita, não chegará a um lugar tão importante para ele quanto ter a companhia (garantida) de outros indivíduos. Vive-se um mundo globalizado e repleto de estímulos. Vivem-se paradigmas que são vinculados estreitamente a uma filosofia utilitarista. Então, se ler e escrever são coisas inúteis, nesse mundo que aí está, para que fazer isso? O fato é que o social empurra o estudante para uma situação em que ele precisa optar dentre mil e uma prioridades

\footnotetext{
${ }^{10}$ Segundo Aron, ainda é atual o estudo da metodologia durkheimiana, especialmente para compreendermos a evolução da ciência. "Admiramos a análise estatística das causas do suicídio como uma etapa da ciência... mas deixamos de nos interessar pelas idéias políticas de Durkheim e pelas teorias morais que ele pretendia difundir nas escolas de formação de professores." (ARON, 2002, p. 823). Neste trabalho, foi tomada emprestada do pensador francês sua explicação sobre o individualismo na ação solitária do indivíduo pressionado pela consciência coletiva e que comete o suicídio. Não interessaram demais ideologias e muito menos desenvolver uma pesquisa com base na filosofia positivista herdada por Durkheim de Auguste Comte.
} 
- e uma delas é ler e escrever. Assim, podemos dizer que a ausência intelectual é um exemplo eloqüente do individualismo. Pior: os estudantes entendem que têm o poder de decisão sobre o que ler, ou não ler, escrever, ou não escrever. Não sabem, no entanto, que apenas fazem parte de um jogo das forças coletivas.

A dificuldade de ler e escrever, ou de interpretar textos, entre os estudantes de universidade é um fenômeno social que faz companhia à relação individualista da sociedade. Seria, no dizer de Durkheim, uma patologia social, que tem causa na insuficiente integração do indivíduo no espaço da construção do saber e, por conseqüência, da boa leitura e escrita. São poucos os grupos de estudos entre os estudantes nas universidades com o objetivo direto de ler e escrever. Menos ainda são aqueles formados com o envolvimento de professores.

As análises realizadas a partir dos gráficos 1, 2, 3 e 4 demonstram a seguinte lógica: os estudantes sabem da concorrência existente na base de nosso sistema social, entendem que isso não os separa (em sala de aula), porém, a integração resultante não é suficiente para motivar a leitura e o gosto pela escrita, uma situação que os leva à ausência intelectual. Isso tudo sem saberem por que ela ocorre. Ora, essas são condições reais e objetivas para que a ausência se realize. De nossa parte queremos dizer que o individualismo é o lócus em que se realiza a ausência. As relações entre ausência intelectual e individualismo não foram estudadas, neste artigo, em termos de causa e efeito. $\mathrm{O}$ estudo das relações entre os dois fenômenos sociais mostra que o individualismo é o campo de domínio onde a dificuldade de ler e escrever acontece.

Passemos, então, às análises dos resultados obtidos com os discursos dos estudantes, e que constituem a perspectiva subjetiva da pesquisa, feitas com inspiração em Max Weber.

Parte-se do pressuposto weberiano de que a sociologia busca compreender a ação social. Esta, para ele, é a conduta humana dotada de sentido, ou seja, uma justificativa subjetivamente elaborada. Cada indivíduo, em Weber, é o agente social que dá sentido à sua ação, a qual pode ter como motivo a tradição, a razão (em relação a um objetivo ou a um valor) ou a emoção (ARON, 1999, 727-728).

As análises que se seguem, dos discursos dos estudantes, enfatizam a ação em relação a um objetivo. Neste caso, o ator (estudante) concebe claramente seu objetivo e combina meios para atingi-los. Neste método de análise, é imperativo que a racionalidade seja definida com base nos conhecimentos do ator e não do observador (pesquisador). Portanto, ao contrário dos procedimentos adotados nas análises das respostas dadas pelos estudantes nas questões direcionadas, em que o pesquisador observou (as respostas) e pôde fazer conclusões, o ponto importante a partir de agora é compreender o que dizem os sujeitos da pesquisa em seus discursos espontâneos.

Para que isso? O objetivo da pesquisa foi obter, em duas perspectivas, sendo uma objetiva e outra subjetiva, a explicação do fenômeno social estudado, que é a ausência intelectual, em suas vinculações com o individualismo, considerando as três hipóteses. Assim como na análise das respostas oferecidas pelos estudantes às questões (afirmativas) constantes do roteiro, essas hipóteses ficaram comprovadas com as interpretações das falas dos estudantes também registradas naquele documento de pesquisa.

Nos discursos ficou provado que os estudantes estão conscientes de que a concorrência permanece na base da organização social e que isso não impede a integração entre eles (hipótese 01). A afirmação do estudante de Direito de que "a maioria dos alunos não estão preocupados em saber ler e escrever, mas sim no mercado de trabalho" mostra a tranqüilidade como a concorrência é vista pelo estudante na dimensão econômica da sociedade. Outro estudante, do mesmo curso, confirma essa percepção, pois coloca a responsabilidade da ausência intelectual nos alunos - ele acredita piamente que "o principal 
interessado é e deve sempre ser o aluno, portanto, a iniciativa tem que partir deste". Não surge, nesses discursos, a possibilidade de uma integração entre os estudantes com o objetivo de aprimorar o ato de ler e escrever. Esse mesmo estudante, no entanto, admite a presença de outro ator no processo ler/ escrever, que é o professor. No seu discurso, diz que "o profissional que leciona, é incumbido de auxiliar o aluno, aperfeiçoar o que ele aprende ao longo de anos de estudo".

Dentre os cinco discursos, dos estudantes de Administração de Empresas, apenas um deles não inclui a presença de outro ator no processo ler/escrever.

No caso dos cinco estudantes de Direito, essa presença foi de cem por cento. Todos incluíram o professor, o coordenador, o país ou a universidade.

Essa existência do outro, no entanto, não é suficiente para eliminar a ausência (comprovação da hipótese 02). Há um pouco de integração, admitem os estudantes, mas não o bastante para que haja um gosto pela leitura e pela escrita. É o que se verifica no discurso do aluno de Administração de Empresas: "deveria haver mais o incentivo dos professores para que isso (ler e escrever) possa melhorar". O mesmo é dito por outro estudante, agora de Direito: "os alunos não apresentam a motivação e orientação necessárias para que possa, por iniciativa própria, selecionar o que vai ler ou escrever. Isso obriga aos professores $e$ coordenadores estabelecerem os assuntos a serem estudados e quais metas/prazos estipulados para leitura e produção de textos".

Por último, foi possível ver nos discursos a dificuldade dos estudantes em perceber a verdadeira causa da ausência (hipótese 03). Nenhum discurso foi encaminhado no sentido de que a leitura e a escrita são partes integrantes da aventura humana de aprender, compreender o mundo, utilizando letras. E que isso acontece no encontro de idéias e atitudes. Longe disso, os estudantes circunscrevem as causas da ausência ao econômico (os livros passam do orçamento das famílias brasileiras), à atitude individual (existe a preguiça mental), ao mercado (o diploma às vezes tem mais valor que uma formação acadêmica proveitosa).

Considerando os níveis de aproximação entre a ausência intelectual e o individualismo, identificados pelas situações comprovadas nas hipóteses, verificam-se duas situações.

Na primeira, talvez por se sentirem mais seguros diante da dureza da concorrência e do individualismo existente no mundo lá fora (extra-universidade), os estudantes se aproximam uns dos outros, ainda que não surja como objetivo principal o estudo dos assuntos do curso. Neste caso, há um distanciamento do individualismo, surgindo oportunidades de maior integração, formação de grupos de estudo, portanto, chances de melhorar a leitura e a escrita com os resultados desses estudos.

Na segunda situação, em que os estudantes experimentam a sensação de segurança pela aproximação mais ou menos permanente entre eles (no mínimo seis meses na mesma turma) os grupos se fortalecem. Neste caso, aumenta o distanciamento do individualismo e surgem novas oportunidades de uma maior integração, de novas formações de grupos de estudo. Claro, fortalecidos os grupos iniciais, afasta-se do individualismo e formam-se novos grupos. No entanto, ao contrário da primeira situação, verificaram-se pela pesquisa menores chances de melhorar a leitura e a escrita com os resultados dos estudos.

Isso é paradoxal, pois o esperado é que com a formação de grupos - entendida aqui como a intenção de ler e escrever - houvesse mais chance de redução da ausência intelectual. Por que isso não acontece?

A explicação está no fato de que os estudantes não estão certos dos motivos pelos quais não lêem e não escrevem melhor. Não sabem as verdadeiras razões disso. É que a aproximação entre eles, na sala de aula, não é no sentido da problematização da realidade. 
Ela não ocorre no nível da discussão intelectual dos assuntos postos pelo professor. Muitas vezes, até, os alunos se aproximam uns dos outros para fugir de discussões desse tipo. Entre os grupos, ocorrem bate-papos estranhos ao tema proposto pelo educador, desperdiçando-se oportunidades.

Um exemplo representativo da não problematização da realidade, observado pelo professor-pesquisador, está no depoimento de uma aluna do curso de Direito, participante da pesquisa, durante uma aula em que era aplicada uma atividade, de leitura e escrita, relacionada ao conteúdo curricular: "não sabemos ler e escrever porque não fomos acostumados a fazer isso pelos professores desde cedo". Na verdade, não ler e não escrever significa aqui não problematizar a realidade. Muitos alunos até lêem; por prazer, por exemplo. Mas, o verdadeiro prazer não deve reduzir-se ao simples ato de ler. Deve ampliar-se à obtenção de respostas a questões científicas e elaboração de novas perguntas, por meio da leitura de textos, com a problematização da realidade.

Em síntese, vimos que existem as condições objetivas para que os estudantes formem grupos de leitura e escrita, mas os estudantes não sabem como fazer isso nem porque não lêem e não escrevem. Eles não percebem que o aprendizado (ler e escrever) acontece no diálogo entre consciências, na identificação de problemas reais e na sua discussão, visando encontrar possíveis soluções - não permanentes, é claro, mas que possibilitem continuar o diálogo intelectual. Há um vínculo entre a ausência intelectual e o distanciamento intelectual entre os estudantes, provocado pelo individualismo.

Como, então, promover a presença intelectual?

Embora a prioridade dos estudos não tenha sido a busca de relações de causa e efeito e de apresentação de soluções, mas, sim, o de discutir as relações que existem entre a dificuldade que os alunos universitários encontram na leitura e na escrita e o individualismo, enumeram-se, a seguir, algumas práticas em sala de aula baseadas nos discursos, que podem ser aplicadas pelos professores visando promover essa presença:

a) As metodologias que incluem a leitura e a escrita, em sala de aula, devem ser utilizadas com mais freqüência. Os alunos entendem que deveria haver mais incentivo dos professores para que a leitura e a escrita melhorassem;

b) A técnica de formação de grupos (painel simples e integrado) deve ser aplicada, acompanhada de breves exposições dos professores, bem como por participações destes nos grupos de discussão;

c) A prática dessa metodologia deve ser permanente. Os alunos entendem que o grande problema é a falta de estímulo à leitura no período de formação do indivíduoestudante. Cabe ao professor encontrar a forma mais criativa e adequada para que os alunos se envolvam, cada vez mais, com a leitura e a escrita;

d) Atividades que mobilizem os alunos, na sala de aula, devem ser postas em prática. A falta de hábito de leitura e escrita, proveniente dos bancos escolares, atinge os universitários, tornando-os alheios à sua realidade e presos ao conceito "só leio o que gosto". Eles se vêem sem coragem para ler/escrever, embora admitam que seja necessário fazer isso;

e) Devem ser realizados vínculos entre os conteúdos dos cursos e a futura profissão dos estudantes, buscando meios de mostrar a importância da leitura e da escrita no dia-adia de trabalho. Os alunos têm dificuldade de perceber esses vínculos e informam que o diploma, às vezes, é mais valorizado do que uma formação acadêmica proveitosa;

f) As metodologias aplicadas em sala de aula devem deixar claro aos estudantes que a boa leitura e escrita podem ser um diferencial de mercado. 


\section{Referências}

Bibliográficas:

1. ARON, Raymond. As etapas do pensamento sociológico. Trad. Sérgio Bath. 6.ed. São Paulo: Martins Fontes, 2002.

2. BOURDIEU, Pierre. O poder simbólico. 9.ed. Trad. Fernando Tomaz. Rio de Janeiro: Bertrand Brasil, 2006.

3. CHRISTIAN, Laville; DIONNE, Jean. A construção do saber: manual de metodologia da pesquisa em ciências humanas. Trad. Heloisa Monteiro e Francisco Settineri. Porto Alegre: Artes Médicas Sul Ltda; Belo Horizonte: Editora UFMG, 1999.

4. COSTA, Maria Cristina Castilho. Sociologia: introdução à ciência da sociedade. 3.ed. São Paulo: Moderna, 2005.

5. DURKHEIM, Émile. As regras do método sociológico. Trad. Pietro Nassetti. São Paulo: Martin Claret, 2006. Coleção A Obra Prima de Cada Autor.

6. GIL, Antonio Carlos. Como elaborar projetos de pesquisa. 4.ed. São Paulo: Atlas, 2002.

7. Metodologia do ensino superior. 3.ed. São Paulo: Atlas, 1997.

8. WEBER, Max. Ciência e política. Trad. Jean Melville. São Paulo: Martin Claret, 2006. Coleção A Obra Prima de Cada Autor.

Jornais:

9. Correio Brasiliense, Brasília, 11 de junho de 2006.

Sítios:

10. http://www.educacao.mg.gov.br. 